\title{
Adsorption of Bromothymol Blue (BTB) Dye Using Four Zeolites as Adsorbent
}

\author{
A. Tabti, ${ }^{a},{ }^{*}$ F. Djafri, ${ }^{b}$ F. Launay, ${ }^{c}$ M. Serier, and I. Benchikh ${ }^{\text {b }}$ \\ a Institute of Science and Technology, Ahmed ZABANA University - Relizane, Bourmadia, \\ 48000 Relizane, Algeria \\ b Laboratory of Chemistry of Materials (LCM), Faculty of Sciences Exact and Applied University \\ of Oran1 - Ahmed Ben Bella, B.P.1524-El M'naouer 31 000, Oran, Algeria \\ 'Surface Reactivity Laboratory, Site Raphael, 3 street Gallilee, 94200 Ivry-sur-Seine, Sorbonne \\ University, UMPC-Paris 06, UMR 7197, France
}

\begin{abstract}
This study examined adsorption of anionic dye on four zeolitic materials incorporated (VS-1, CuZSM-5) and not incorporated into metals (S-1, ZSM-5). The adsorption of the bromothymol blue (BTB) dye on the four adsorbents was analysed using isotherm models Langmuir, Freundlich, and Temkin. Two kinetic models were also applied to study the adsorption process, pseudo-first order and pseudo-second order. The isothermal data showed good correlation. The kinetics of adsorption were better described by the pseudo-second order model. The results obtained indicate that the maximum percentage removal of the BTB dye was given by a purely non-incorporated silicic zeolite (S-1).
\end{abstract}

Keywords

Zeolites, adsorption isotherm, bromothymol blue, dye degradation

\section{Introduction}

The environment is now an integral part of the development strategies designed and implemented in every country in the world. The most important source of pollution comes from industrial activities, where effluents from industry have an adverse impact on human health. These effluents are mainly made up of dyes.

The industrial developments of recent years have left their negative impressions the environment. Such industries include the manufacture of dyes, textile, printing, paper, leather, cosmetics, and many others that use dyes and dyeing processes to produce their finished products. ${ }^{1}$

The dyes used in the textile industry are classified into three classes: anionic (which include direct dyes, acid and reactive), cationic which include all basic dyes, and non-ionic which include dispersed dyes. ${ }^{2}$

Dyes have a synthetic origin and complex aromatic molecular structure, which makes them more stable and more difficult for biodegradation and photodegradation. ${ }^{3,4}$

There are several techniques that are used to remove dyes, however, adsorption is the most effective method due to its simplicity, high yield, easy recovery, and reuse of the adsorbent. ${ }^{5}$

The dye used in this study was a triphenylmethane dye bromothymol blue (BTB), which belongs to the family of anionic dyes. BTB is a chemical compound often used as a

\footnotetext{
* Corresponding author: Affaf Tabti, doctor

Email: affaf.affaf@yahoo.fr
}

coloured indicator of $\mathrm{pH}$, and it has halochromic properties. The acid form is yellow $(\mathrm{pH}<7)$ and the basic form is blue $(\mathrm{pH}>7)$. It is widely used in biomedical, biological, and chemical engineering applications.

The degradation of this dye has been studied by many researchers. H. Ayoub et al. ${ }^{6}$ carried out photodegradation of the dye (BTB) using $\mathrm{TiO}_{2}$ as a catalyst. In their work, $L$. Cao et al. ${ }^{7}$ and M. S. E. Farida et al. ${ }^{8}$ studied the adsorption of BTB on QCF (quaternized cellulose fibres) and on bentonite carbon composite, respectively. M. Ghaedi et al. ${ }^{9}$ and H.Tavakkoli et al. ${ }^{10}$ used gold nanoparticle-loaded activated carbon (Au-NP-AC) and nanoparticles of perovskite type for the elimination of BTB. Y. Zheng et al. ${ }^{11}$ studied the photocatalytic performance of $\mathrm{MgO}$ in the degradation of BTB. A. Ameri et al. ${ }^{12}$ carried out a photocatalytic bleaching of BTB using biogenic selenium nanoparticles.

In this paper, we present an adsorption study of bromothymol blue dye on four zeolitic materials. Isotherm and kinetic models were used to follow the adsorption process of the dye studied.

\section{Experimental}

\subsection{Synthesis of materials}

The synthesis of the materials was carried out according to a protocol by following the molar composition of each material. The molar composition of each zeolite is presented in Table 1. 
Table 1 - Molar composition of four materials (S-1, ZSM-5, VS-1, and CuZSM-5)

\begin{tabular}{c|c}
\hline Zeolites & Molar composition \\
\hline S-1 & $\mathrm{KF}-0.08 \mathrm{TPAOH}-\mathrm{SiO}_{2}-20 \mathrm{H}_{2} \mathrm{O}$ \\
\hline ZSM-5 & $\mathrm{SiO}_{2}-0.02 \mathrm{Al}_{2} \mathrm{O}_{3}-0.275 \mathrm{TPABr}-1.13 \mathrm{CH}_{3} \mathrm{NH}_{2}-7.5 \mathrm{H}_{2} \mathrm{O}$ \\
\hline VS-1 & $\mathrm{KF}-0.08 \mathrm{TPAOH}-\mathrm{SiO}_{2}-0.01 \mathrm{VOSO}_{4}-20 \mathrm{H}_{2} \mathrm{O}$ \\
\hline CuZSM-5 & $\mathrm{SiO}_{2}-0.02 \mathrm{Al}_{2} \mathrm{O}_{3}-0.275 \mathrm{TPABr}-0.01 \mathrm{Cu}\left(\mathrm{NO}_{3}\right)_{2}, 3 \mathrm{H}_{2} \mathrm{O}-1.13 \mathrm{CH}_{3} \mathrm{NH}_{2}-7.5 \mathrm{H}_{2} \mathrm{O}$ \\
\hline
\end{tabular}

Zeolites (S-1 and ZSM-5) were synthesised from mixtures containing the following reagents: for zeolite $(\mathrm{S}-1)-$ Ludox (a source of silica), tetrapropylammonium hydroxide $(\mathrm{TPAOH})$, potassium fluoride $(\mathrm{KF})$, and demineralised water; for zeolite (ZSM-5) - Ludox, tetrapropylammonium bromide (TPABr), $\mathrm{Al}_{2} \mathrm{O}_{3}$ (aluminum source), methylamine $\left(\mathrm{CH}_{3} \mathrm{NH}_{2}\right)$, and demineralised water.

The incorporated zeolites (VS-1 and CuZSM-5) were synthesised from gel containing the reagents: for zeolite (VS-1) - Ludox, TPAOH, $\mathrm{VOSO}_{4}$ (source of the metal), $\mathrm{KF}$, and demineralised water; for zeolite (CuZSM-5) - Ludox, TPABr, $\mathrm{Al}_{2} \mathrm{O}_{3}, \mathrm{Cu}\left(\mathrm{NO}_{3}\right)_{2}, 3 \mathrm{H}_{2} \mathrm{O}$ (source of the metal), $\mathrm{CH}_{3} \mathrm{NH}_{2}$, and demineralised water.

The incorporation of metals in these materials (VS-1, CuZSM-5) and materials not incorporated (S-1, ZSM-5) were synthesized under the temperature conditions of $175^{\circ} \mathrm{C}$ and duration of crystallisation of $24 \mathrm{~h}$.

The materials obtained were characterised by X-ray diffraction and UV-Vis spectroscopy. The results showed that the synthesised zeolites presented a high crystallinity with an MFI type structure.

\subsection{Adsorption experiments}

The procedure for adsorption of BTB dye was as follows: $100 \mathrm{ml}$ of the dye solution prepared at $10 \mathrm{mg} \mathrm{I}^{-1}$ was poured into beakers, followed by the addition of $50 \mathrm{mg}$ of zeolites (1, 2, 3, and 4). The mixtures were stirred for $2 \mathrm{~h}$, and the $\mathrm{pH}$ of the solution was measured every $10 \mathrm{~min}$. The mixtures were then filtered using an EBA-Hetlich centrifuge at a speed of $3500 \mathrm{rpm}$ for $15 \mathrm{~min}$.

The absorbance of bromothymol blue solution was measured as the $\mathrm{pH}$ of the solution varied.

Before starting the dye adsorption study it is necessary to determine the wavelength $\left(\lambda_{\max }\right)$ at which absorbance is maximum. When the dye solution is in basic form $(\mathrm{pH}>7)$, the wavelength $\left(\lambda_{\max }\right)$ is equal to $615 \mathrm{~nm}$, while the neutral form and the acid form $(\mathrm{pH} \leq 7)$ of the dye solution have superimposed peaks, the wavelength $\left(\lambda_{\max }\right)$ is equal to $430 \mathrm{~nm}$.

When the $\mathrm{pH}$ of the solution changes, a different peak in the UV-Vis spectrum (variation of $\lambda_{\max }$ ) is observed, and consequently, an evolution in the colour of the BTB solution.
In our case, the solution prepared at $10 \mathrm{mg} \mathrm{I}^{-1}$ of the BBT dye chosen for the determination of the maximum wavelength $\left(\lambda_{\max }\right)$ of the dye, presents a visible band located at $435 \mathrm{~nm}$.

\subsection{Adsorption kinetics and isotherms}

\subsubsection{Study of the adsorption kinetics}

Kinetic models were considered to analyse the experimental results obtained. Two models were studied in order to describe the adsorption phenomenon of the BTB dye on the four catalysts used: the pseudo-first-order model (Eq. (2)), and the pseudo-second-order model (Eq. (3)). ${ }^{13}$ The kinetics of adsorption of the dye studied (BTB) were carried out for an initial dye concentration of $10 \mathrm{mgl}^{-1}$, with a concentration of $0.50 \mathrm{gl}^{-1}$ for the four types of zeolites (S-1, ZSM-5) and (VS-1, CuZSM-5).

The adsorption efficiency of the dye on the four catalysts is defined by ${ }^{18}$ :

$$
R \%=\left[\frac{\left(C_{0}-C_{\mathrm{t}}\right)}{C_{0}}\right] \cdot 100
$$

where $c_{0}$ is the initial concentration of the substrate $\left(\mathrm{mgl}^{-1}\right)$ and $C_{\mathrm{t}}$ is the concentration of the substrate at equilibrium of the adsorption process $\left(\mathrm{mgl}^{-1}\right)$.

The kinetic equation of pseudo-first-order is represented below by the following linear relation:

$$
\log \left(q_{\mathrm{e}}-q_{\mathrm{t}}\right)=\log q_{\mathrm{e}}-\left(\frac{k_{1}}{2.303}\right) t
$$

where $q_{\mathrm{t}}\left(\mathrm{mgg}^{-1}\right)$ and $q_{\mathrm{e}}\left(\mathrm{mgg}^{-1}\right)$ are the adsorption capacities at a given time $t(\mathrm{~min})$ and the equilibrium condition, respectively, and $k_{1}\left(\mathrm{~min}^{-1}\right)$ is the pseudo-first-order constant.

The second model is represented by the following formula:

$$
\frac{t}{q_{\mathrm{t}}}=\frac{1}{k_{2} q_{\mathrm{e}}^{2}}+\frac{t}{q_{\mathrm{e}}}
$$

where $q_{\mathrm{t}}$ is the quantity of the dye adsorbed at time $\mathrm{t}$ $\left(\mathrm{mg} \mathrm{g}^{-1}\right), q_{\mathrm{e}}$ is the maximum adsorption capacity of the pseudo-second-order $\left(\mathrm{mgg}^{-1}\right)$, and $k_{2}$ is the kinetic constant of adsorption of the pseudo-second-order $\left(\mathrm{g} \mathrm{mg}^{-1} \mathrm{~min}^{-1}\right)$. 


\subsubsection{Adsorption isotherms}

Adsorption isotherms play an important role in determination of maximum adsorption capacities and in the design of new adsorbents. There are many theoretical models to describe the adsorption isotherms. This study included only the Langmuir Eq. (4), ${ }^{14}$ Freundlich Eq. (5), ${ }^{15}$ and Temkin Eq. (6) ${ }^{16}$ models. These models are given by the following equations:

$$
\begin{aligned}
& \frac{c_{\mathrm{e}}}{q_{\mathrm{e}}}=\frac{1}{q_{\max } K_{\mathrm{L}}}+\frac{1}{q_{\max } c_{\mathrm{e}}} \\
& \ln q_{\mathrm{e}}=\ln K_{\mathrm{F}}+\frac{1}{n} \ln c_{\mathrm{e}} \\
& q_{\mathrm{e}}=b \ln K_{\mathrm{t}}+b \ln c_{\mathrm{e}}
\end{aligned}
$$

$K_{\mathrm{L}}$ is the Langmuir adsorption equilibrium, constant $q_{\max }$ $\left(\mathrm{mg} \mathrm{g}^{-1}\right)$ represents the maximum adsorption capacity, $K_{\mathrm{f}}$ is the Freundlich constant $\left(\mathrm{kg}^{-1}\right), 1 / n$ is the heterogeneity factor, $b$ is the variation of adsorption energy $\left(\mathrm{mol}^{-1}\right)$, and $K_{\mathrm{T}}$ is Temkin constant $\left(\mathrm{Img}^{-1}\right)$.

\section{Results and discussion}

\subsection{Adsorption kinetics}

Concerning pseudo-first-order kinetics, the plot of $\ln \left(q_{\mathrm{e}}-q_{\mathrm{t}}\right)$ as a function of time for the dye studied gives a linear form (Fig. 1), and pseudo-second-order was examined by plotting $t / q_{\mathrm{t}}$ as a function of time (Fig. 2).

All the kinetic parameters determined from these lines are presented in Table 2 on the zeolites S-1, ZSM-5, VS-1, and CuZSM-5, respectively.
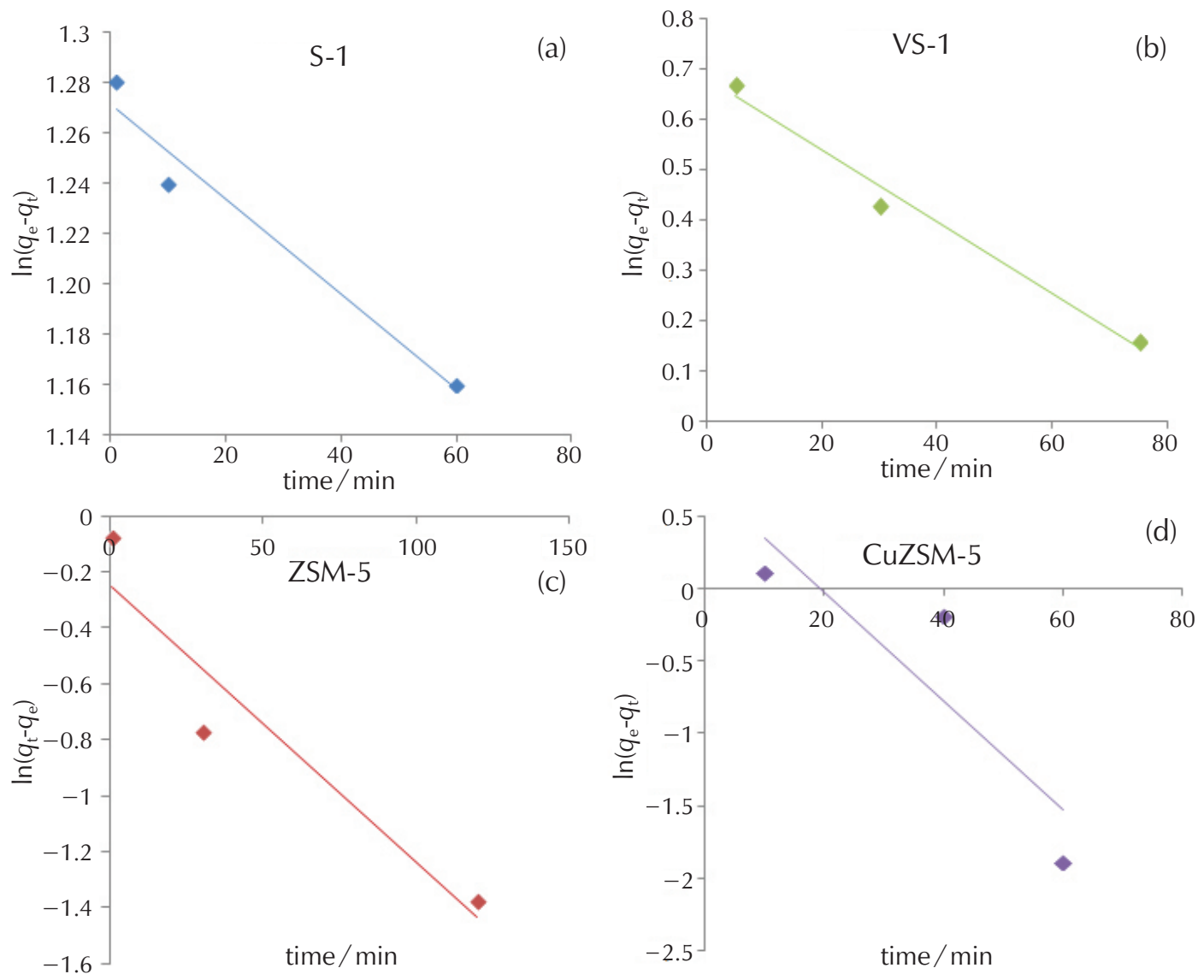

Fig. 1 - Pseudo-first-order kinetics of bromothymol blue on the four zeolites

Table 2 - Kinetic adsorption constants of the dye studied for the two models on the four materials (S-1, ZSM-5, VS-1, and CuZSM-5)

\begin{tabular}{l|c|c|c|c|c|c|c|c}
\hline \multirow{2}{*}{ Dye } & Zeolites & & \multicolumn{3}{|c|}{ Pseudo-first-order } & \multicolumn{3}{c}{ Pseudo-second-order } \\
\hline \multirow{4}{*}{ BTB } & & $q_{\mathrm{e}}$ (exp) $/ \mathrm{mgg}^{-1}$ & $q_{\mathrm{e}}(\mathrm{cal}) / \mathrm{mgg}^{-1}$ & $k_{1} / \mathrm{min}^{-1}$ & $R^{2}$ & $q_{\mathrm{e}}(\mathrm{cal}) / \mathrm{mgg}^{-1}$ & $k_{2} / \mathrm{g} \mathrm{mg}^{-1} \mathrm{~min}^{-1}$ & $R^{2}$ \\
\cline { 2 - 9 } & $\mathrm{S}-1$ & 16.70 & 0.477 & 0.0019 & 0.963 & 16.583 & $1.530 \cdot 10^{-2}$ & 0.985 \\
\cline { 2 - 9 } & ZSM-5 & 11.92 & 2.808 & 0.0099 & 0.899 & 11.890 & $10.890 \cdot 10^{-2}$ & 0.999 \\
\cline { 2 - 9 } & V S-1 & 12.21 & 0.935 & 0.0071 & 0.978 & 12.019 & $3.309 \cdot 10^{-2}$ & 0.992 \\
\cline { 2 - 9 } & Cu ZSM-5 & 8.75 & 3.906 & 0.0375 & 0.767 & 8.976 & $3.655 \cdot 10^{-2}$ & 0.998 \\
\hline
\end{tabular}



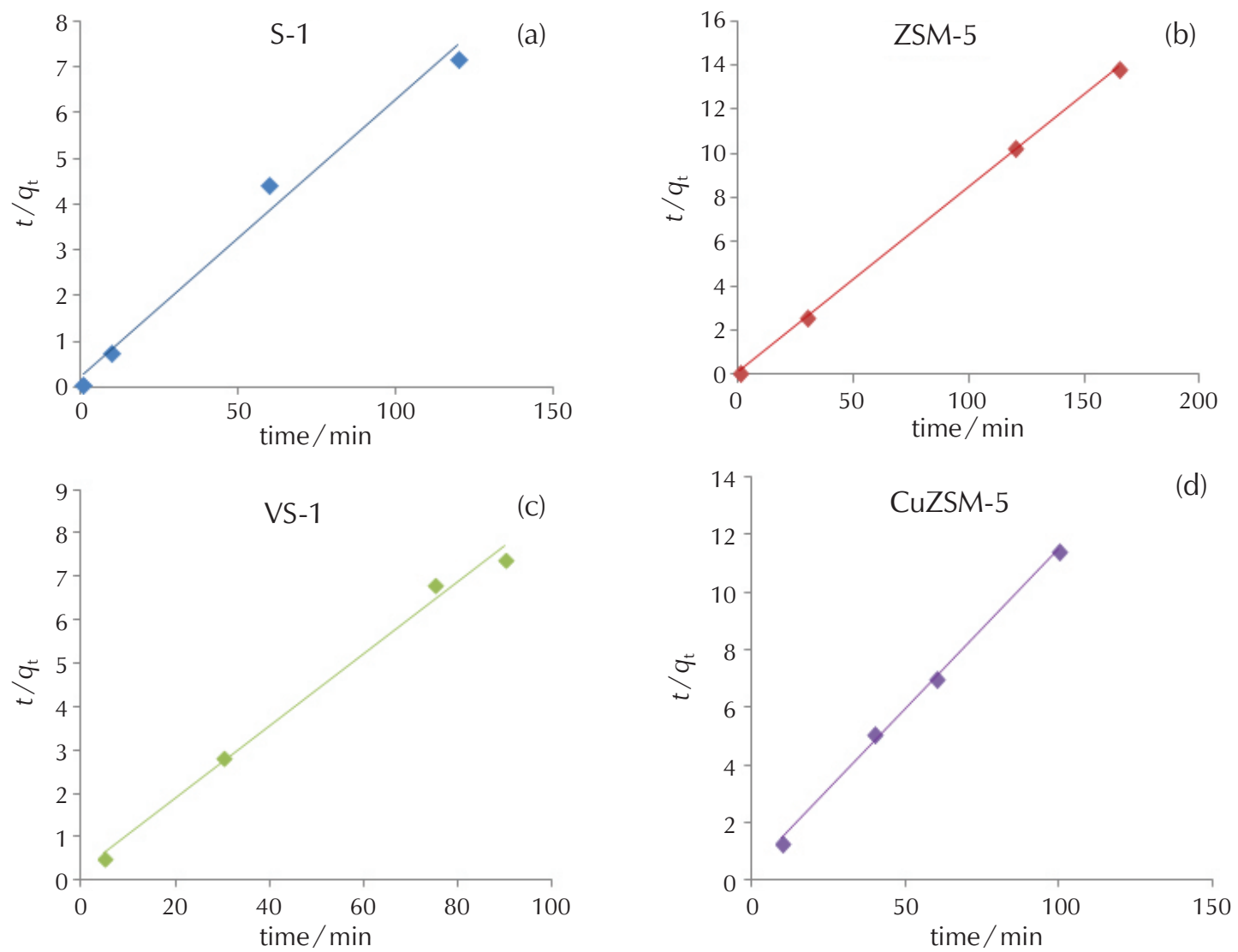

Fig. 2 - Pseudo-second-order kinetics of bromothymol blue on the four zeolites

The results showed that the pseudo-second-order model was more reliable for determining the order of the adsorption kinetics of BTB on the S-1, ZSM-5, VS-1, and CuZSM-5 zeolites, because the correlation coefficients were closer to one $\left(R^{2}>0.99\right)$ compared to those of the pseudo-first-order model.

\subsection{Adsorption isotherms}

The experimental results of the BTB adsorption isotherms on zeolites modelled by the Langmuir, Freundlich, and Temkin equations are shown in Figs. 3, 4, and 5.

The Langmuir, Freundlich and Temkin parameters for the BTB on the four zeolites are presented in Table 3.

The correlation coefficient $R^{2}$ of the Langmuir model is very close to one for the dye on the four zeolites. According to the constants $q_{\max }$ calculated from this model, it was observed that the adsorption capacity of BTB on (S-1) $\left(q_{\max }=11.025 \mathrm{mg} \mathrm{g}^{-1}\right)$ was higher compared to the other zeolites ZSM-5, CuZSM-5, and VS-1 (6.587, 3.345, and $\left.6.317 \mathrm{mg} \mathrm{g}^{-1}\right)$, respectively.

Langmuir isotherm is characterized by the separation factor or equilibrium parameter, $R_{\mathrm{L}}$, which is used to predict whether an adsorption system is "favourable" or "unfa-
Table 3 - Adsorption isotherm constant of the dye studied on the four zeolites (S-1, ZSM-5, VS-1, and CuZSM-5)

\begin{tabular}{c|c|c|c|c}
\hline \multicolumn{5}{c}{ Langmuir } \\
\hline zeolites & $K_{\mathrm{L}}$ & $q_{\max } / \mathrm{mgg}^{-1}$ & $R^{2}$ & $R_{\mathrm{L}}$ \\
\hline S-1 & 1.744 & 11.025 & 0.9993 & 0.0542 \\
\hline ZSM-5 & 0.552 & 6.587 & 0.9990 & 0.1533 \\
\hline CuZSM-5 & 0.287 & 3.345 & 0.9994 & 0.2583 \\
\hline VS-1 & 0.528 & 6.317 & 0.9992 & 0.1592 \\
\hline \multicolumn{5}{|c|}{ Freundlich } \\
\hline zeolites & $K_{\mathrm{F}}$ & $1 / n$ & $R^{2}$ & \\
\hline S-1 & 19.488 & 0.3186 & 0.9984 & \\
\hline ZSM-5 & 32.769 & 0.7336 & 0.9956 & \\
\hline CuZSM-5 & 35.022 & 0.7805 & 0.9964 & \\
\hline VS-1 & 107.77 & 1.4638 & 0.9960 & \\
\hline \multicolumn{5}{|c|}{ Temkin } \\
\hline zeolites & $b / K^{\prime}$ mol & & \\
\hline S-1 & -4.83 & 0.0191 & 0.9991 & \\
\hline ZSM-5 & -8.38 & 0.0601 & 0.9971 & \\
\hline CuZSM-5 & -12.03 & 0.0866 & 0.9985 & \\
\hline VS-1 & -8.52 & 0.0619 & 0.9975 & \\
\hline & & & \\
\hline
\end{tabular}



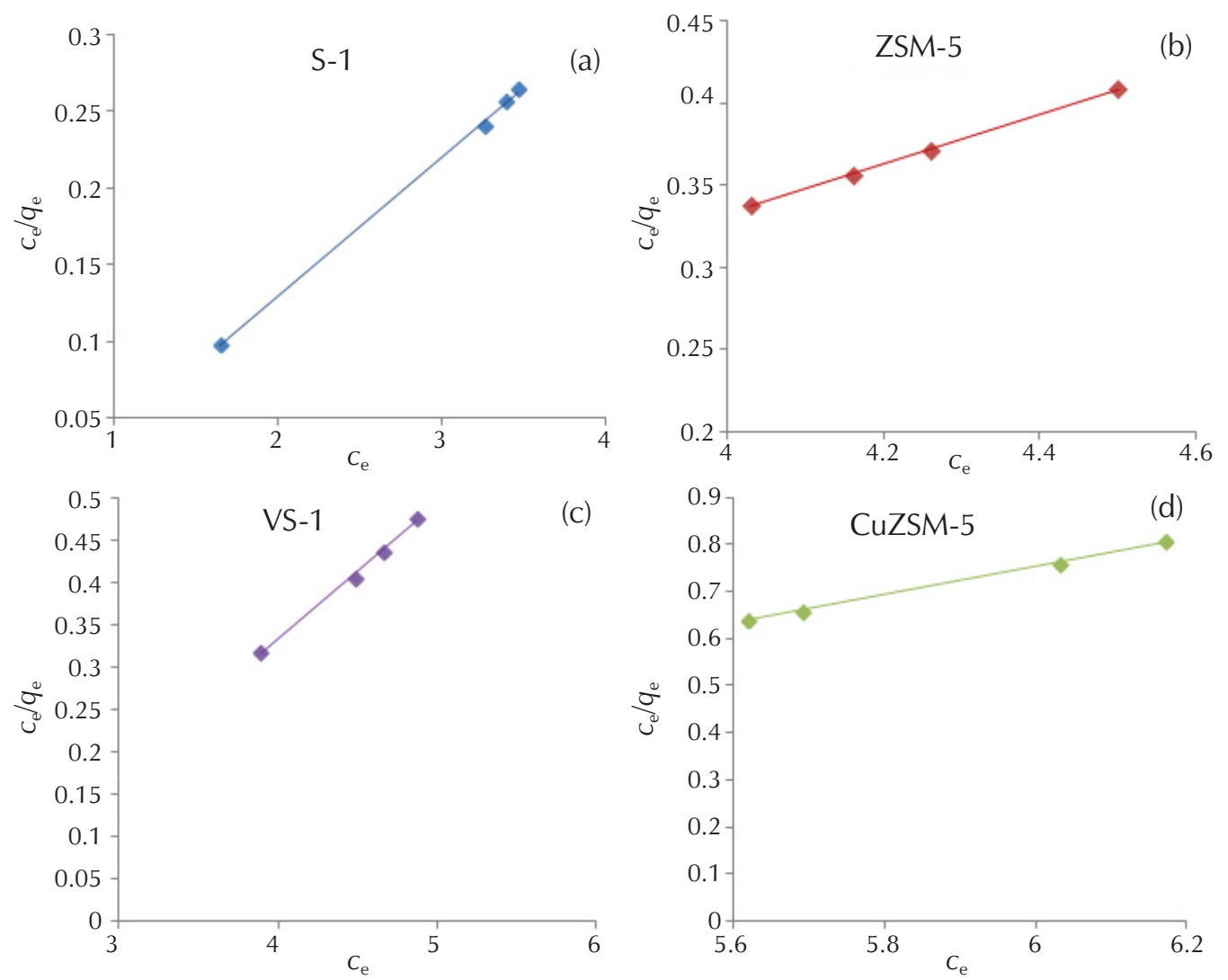

Fig. 3 - Langmuir adsorption isotherm of BTB on the four zeolites
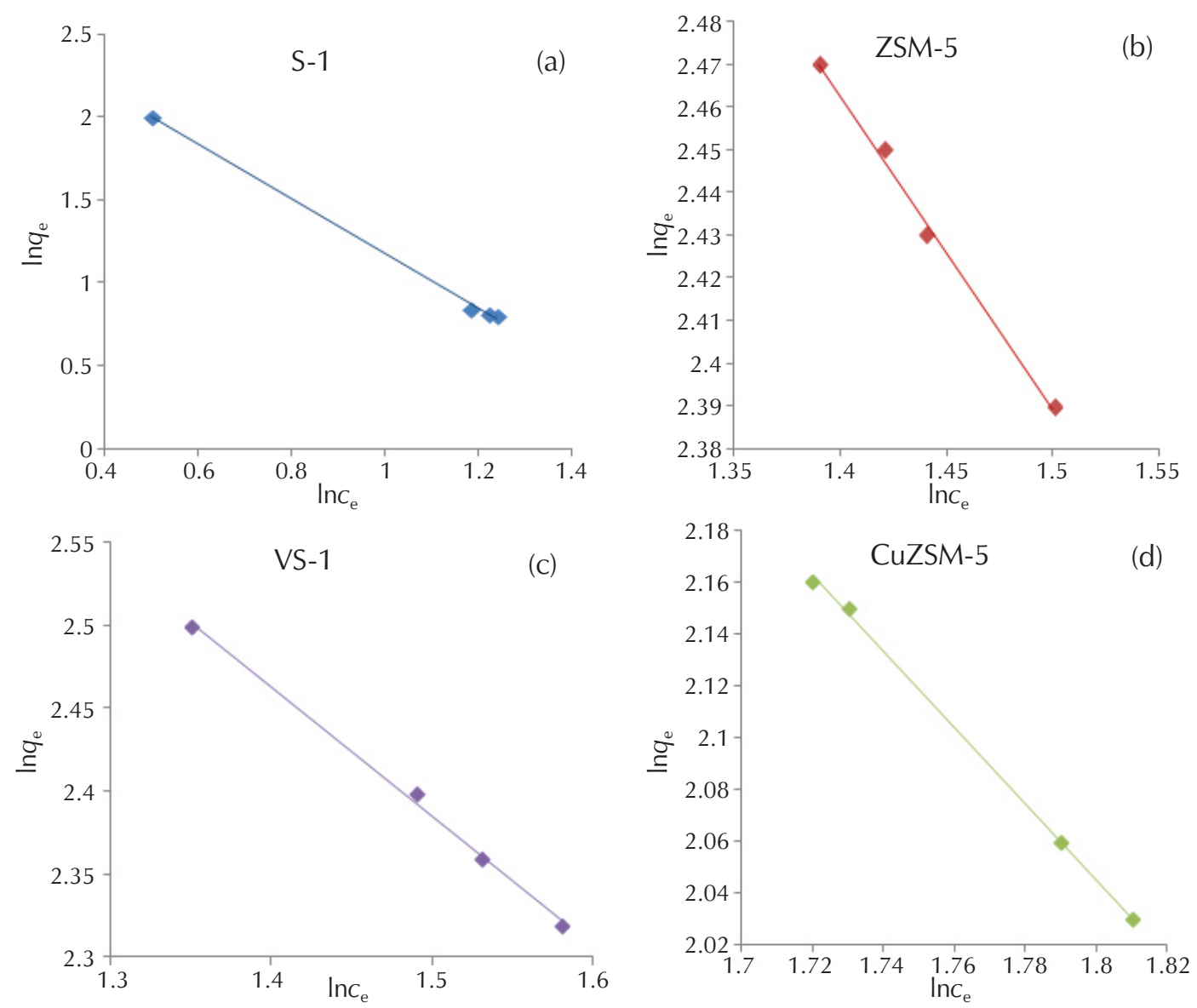

Fig. 4 - Freundlich adsorption isotherm of BTB on the four zeolites 

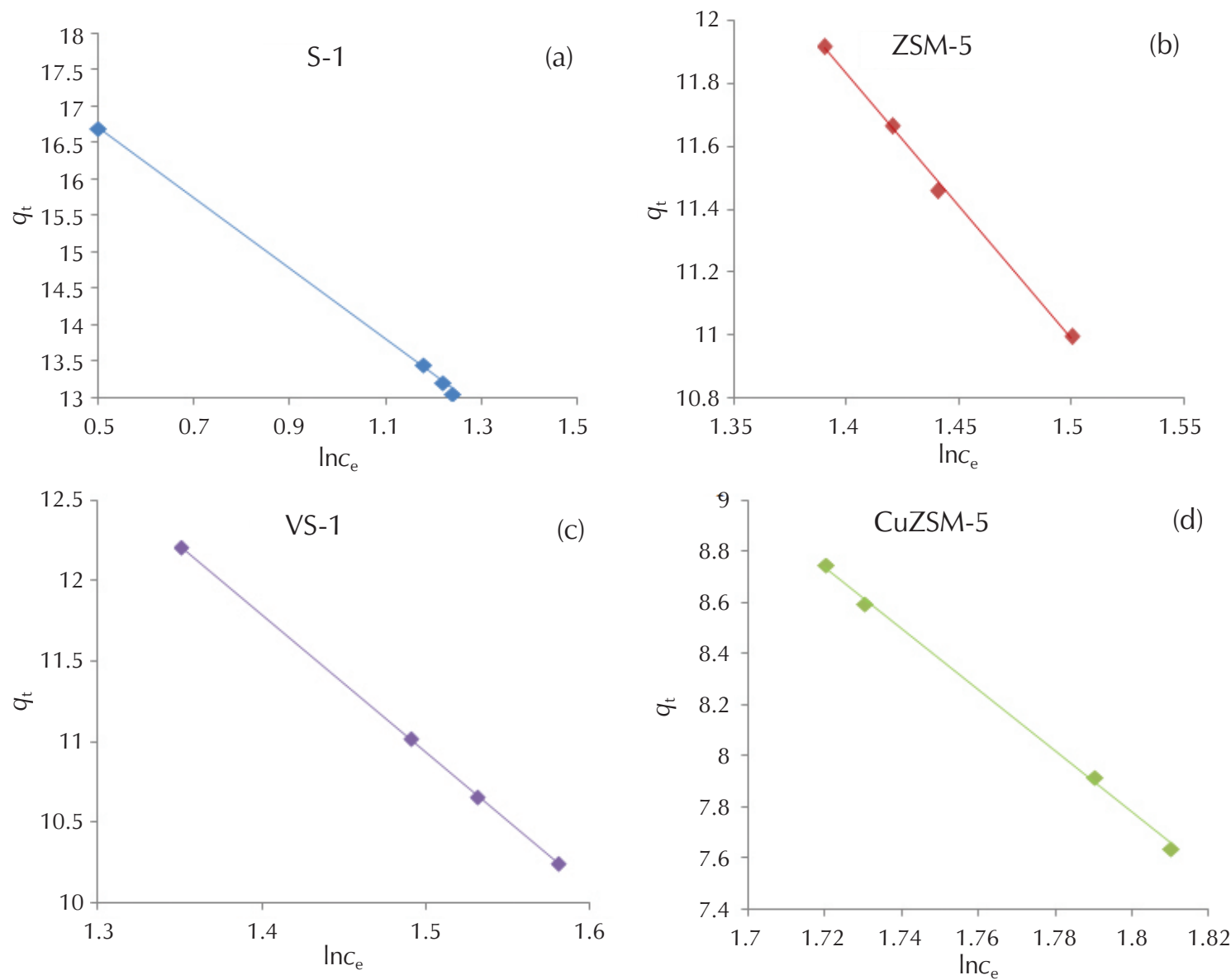

Fig. 5 - Temkin adsorption isotherm of BTB on the four zeolites

vourable". The separation factor, $R_{\mathrm{L}}$, is defined by the following equation: ${ }^{17}$

$$
R_{\mathrm{L}}=\frac{1}{1}+\left(K_{\mathrm{L}} C_{0}\right)
$$

The $R_{\perp}$ values of the dye studied on the four zeolites were in the range of $0<R_{\mathrm{L}}<1$, and are shown in Table 3, which indicates that the adsorption is favourable.

In the case of the Freundlich isotherm, the results showed that the correlation coefficients $R^{2}$ were good in all cases. The values $1 / n$ found suggest better adsorption of the dye on (S-1), easy adsorption of the dye on (ZSM-5 and CuZ$\mathrm{SM}-5)$, and difficult adsorption in the presence of VS-1. Therefore, the adsorption is favourable in the presence of (S-1, ZSM-5, and CuZSM-5). ${ }^{19}$
Regarding the Temkin isotherm, the values of the correlation coefficient $R^{2}$ were also high.

\section{Conclusion}

The results of this study revealed that adsorbent (S-1) highly efficient in the elimination of bromothymol blue, with a percentage of $83.44 \%$ compared to the other adsorbents (ZSM-5, MS-1, and MZSM -5) with elimination percentages of 59.64, 61.07, and $43.75 \%$, respectively. The results of the adsorption isotherms suggest that the Langmuir isotherm presents higher values of the correlation coefficient $R^{2}$ compared to the other isotherm models. The kinetic study showed that the pseudo-second-order model offered a better description of the kinetics of the adsorption reaction for the dye on the four types of zeolites compared to the pseudo-first-order model, indicating a chemical reaction (chemisorption). 


\section{References \\ Literatura}

1. M. A. Mohd Salleh, D. K. Mahmoud, W. A. Abdul Karim, A. Idris, Cationic and anionic dye adsorption by agricultural solid wastes: A comprehensive review, Desalination 280 (2011) 1-13, doi: https://doi.org/10.1016/j.desal.2011.07.019.

2. G. Z. Kyzas, J. F. Matis, K. A., The Change from Past to Future for Adsorbent Materials in Treatment of Dyeing Wastewaters, Materials 6 (2013) 5131-5158, doi: https://doi.org/10.3390/ ma6115131.

3. H. Chen, J. Zheo, Adsorption study for removal of Congo red anionic dye using organo-attapulgite, Adsorption 15 (2009) 381-389, doi: https://doi.org/10.1007/s10450-009-9155-z.

4. B. H. Hameed, A. T. M. Din, A. L. Ahmad, Adsorption of methylene blue onto bamboo-based activated carbon: Kinetics and equilibrium studies, J. Hazard. Mater. 141 (2007) 819825, doi: https://doi.org/10.1016/j.jhazmat.2006.07.049.

5. C. Srilakshmi, R. Saraf, Ag-doped hydroxyapatite as efficient adsorbent for removal of Congo red dye from aqueous solution: Synthesis, kinetic and equilibrium adsorption isotherm analysis, Micropor. Mesopor. Mat. 219 (2016) 134-144, doi: https://doi.org/10.1016/j.micromeso.2015.08.003.

6. H. Ayoub, M. Kassir, M. Raad, H. Bazzi, A. Hijazi, Effect of Dye Structure on the Photodegradation Kinetic Using $\mathrm{TiO}_{2}$ Nanoparticles, J. Chem. Eng. Mater. Sci. 5 (2017) 31-45, doi: https://doi.org/10.4236/msce.2017.56004.

7. L. Cao, T. Liang, X.Zhang, W. Liu, J. Li , X. Zhan, L. Wang, In-Situ $\mathrm{pH}$-Sensitive Fibers via the Anchoring of Bromothymol Blue on Cellulose Grafted with Hydroxypropyltriethylamine Groups via Adsorption, Polymers 10 (2018) 709-722, doi: https://doi.org/10.3390/polym10070709.

8. M. S. E. Farida El-Dar, M. Hamed Ibrahim, A. B. Heba Farag, M. Zakaria Abdelwahhab, M. E. H Shalabi, Preparation, Characterization of Bentonite Carbon Composite and Design Application in Adsorption of Bromothymol Blue Dye, J. Multidiscip. Eng. Sci. Technol. 3 (2016) 3758-3765, url: https://pdfs.semanticscholar.org/3acf/345cc02278a608cdc5f7983ae24ccce5466e.pdf.

9. M. Ghaedi, E. Nazari, R. Sahraie, M. K. Purkait, Kinetic and isotherm study of Bromothymol Blue and Methylene blue removal using Au-NP loaded on activated carbon, Desalin. Water. Treat. 52 (2014) 5504-5512, doi: https://doi.org/10.
1080/19443994.2013.822156.

10. H .Tavakkoli, Z. Zaman, A. Chaemi, $\mathrm{Gd}_{0.5} \mathrm{Y}_{0.5} \mathrm{CrO}_{3}$ Perovskite-Type Oxide Nanopowder: A Novel Adsorbent to Remove Organic Dye from Aqueous Media, J. Chem. Res. 40 (2016) 53-61, doi: https://doi.org/10.3184/17475191 6X14501064417178.

11. Y. Zheng, L. Cao, G. Xing, Z. Bai, J. Huang, Z. Zhang, Microscale flower-like magnesium oxide for highly efficient photocatalytic degradation of organic dyes in aqueous solution, RSC Adv. 9 (2019) 7338-7348, doi: https://doi.org/10.1039/ C8RA10385B.

12. A. Ameri, M. Shakibaie, A. Ameri, M. A. Faramarzi, B. AmirHeidari, H. Forootanfar, Photocatalytic decolorization of bromothymol blue using biogenic selenium nanoparticles synthesized by terrestrial actinomycete Streptomyces griseobrunneus strain FSHH12, Desalin. Water. Treat. 57 (2016) 21552-21563, doi: https://doi.org/10.1080/19443994.201 5.1124349 .

13. S. Gupta, B. V. Babu, Removal of toxic metal $\mathrm{Cr}(\mathrm{VI})$ from aqueous solutions using saw dust as adsorbent: Equilibrium, kinetics and regeneration studies, Chem. Eng. J. 150 (2009) 352-365, doi: https://doi.org/10.1016/j.cej.2009.01.013.

14. I. Langmuir, The Constitution and fundamental properties of solids and liquids part I. solids. J. Am. Chem. Soc. 38 (1916) 2221-2295, doi: https://doi.org/10.1021/ja02268a002.

15. H. M. F. Freundlich, Over the Adsorption in Solution. J. Phys. Chem. 57 (1906) 385-470.

16. M. Temkin, V. Pyzhev, Kinetics of ammonia synthesis on promoted iron catalysts, Acta Physiochimica (USSR) 12 (1940) 217-222.

17. M. Kumar, P. T. Bijay, K. S. Vinod, Crosslinked chitosan/polyvinyl alcohol blend beads for removal and recovery of Cd (II) from wastewater, J. Hazard. Mater. 172 (2009) 1041-1048, doi: https://doi.org/10.1016/j.jhazmat.2009.07.108.

18. H. Y. Zhu, R. Jiang, L. Xiao, Adsorption of an anionic azo dye by chitosan/kaolin $/ \gamma-\mathrm{Fe}_{2} \mathrm{O}_{3}$ composites, Appl. Clay Sci. 48 (2010) 522-526, doi: https://doi.org/10.1016/j. clay.2010.02.003.

19. H. Tang, W. Zhou, L. Zhang, Adsorption isotherms and kinetics studies of malachite green on chitin hydrogels, J. Hazard. Mater. 209-210 (2012) 218-225, doi: https://doi. org/10.1016/j.jhazmat.2012.01.010. 


\section{SAŽETAK \\ Adsorpcija indikatora bromtimol modro (BTB) upotrebom četiri zeolita kao adsorbenata

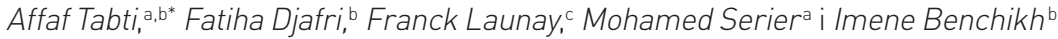

U ovoj je studiji ispitivana adsorpcija anionskih bojila na četiri zeolitska materijala inkorporirana (VS-1, CuZSM-5) i neinkorporirana (S-1, ZSM-5) u metale. Adsorpcija indikatora bromtimol modro (BTB) na četiri adsorbenta analizirana je izotermnim modelima Langmuir, Freundlich i Temkin. Također su primijenjena dva kinetička modela za proučavanje procesa adsorpcije, pseudo-prvog i pseudo-drugog reda. Izotermni podatci pokazali su dobru korelaciju. Kinetiku adsorpcije bolje je opisao model pseudo-drugog reda. Dobiveni rezultati pokazali su da je maksimalni postotak uklanjanja indikatora BTB dobiven čisto neinkorporiranim silicijskim zeolitom (S-1).

Ključne riječi

Zeoliti, adsorpcijska izoterma, bromtimol modro, razgradnja bojila

anstitute of Science and Technology, Ahmed

Izvorni znanstveni rad ZABANA University - Relizane, Bourmadia, 48000 Relizane, Alžir

b Laboratory of Chemistry of Materials (LCM), Prispjelo 2. kolovoza 2020.

Faculty of Sciences Exact and Applied University of Oran1 - Ahmed Ben Bella,

B.P.1524-El M'naouer 31 000, Oran, Alžir

' Surface Reactivity Laboratory, Site Raphael,

3 street Gallilee, 94200 Ivry-sur-Seine,

Sorbonne University, UMPC-Paris 06, UMR

7197, Francuska 